\title{
What do digital inclusion and data literacy mean today?
}

\section{Elinor Carmi}

Department of Communication and Media, University of Liverpool, United Kingdom, Elinor.Carmi@liverpool.ac.uk

\section{Simeon J. Yates}

Department of Communication and Media, University of Liverpool, United Kingdom

Published on 27 May 2020 | DOI: 10.14763/2020.2.1474

\begin{abstract}
As more of our everyday lives become digital, it has become crucial to include everyone in the digital society. This special issue is examining the different layers of digital inclusion and data literacy by drawing on research, policy, and practice developments around literacies in various regions and contexts. It highlights the politics around them so as to propose policies that are needed to include more people in datafied societies, and what types of literacies they should learn. This issue includes three commentaries by experts in the field and five peer-reviewed academic papers that go towards tackling digital inclusion. This means to find solutions to the fact that many people are left behind technological advancements, and that these create what is commonly called - the digital divide.
\end{abstract}

Keywords: Digital inclusion, Data literacy

\section{Article information}

Published: 27 May 2020

Licence: Creative Commons Attribution 3.0 Germany

Funding: Me and My Big Data: Developing Citizen's Data Literacy. Funded by the Nuffield Foundation.

Competing interests: The author has declared that no competing interests exist that have influenced

the text.

URL: http://policyreview.info/digital-inclusion

Citation: Carmi, E. \& Yates, S. J. (2020). What do digital inclusion and data literacy mean today? Internet Policy Review, 9(2). DOI: 10.14763/2020.2.1474 


\section{PAPERS IN THIS SPECIAL ISSUE}

What do digital inclusion and data literacy mean today?

Elinor Carmi, University of Liverpool

Simeon J. Yates, University of Liverpool

Apps, appointments, panic and people

Alice Mathers, Good Things Foundation

Want to open the budget now? Ask me how!

Mary Loitsker, Public Knowledge Workshop

Digital inclusion and well-being

Douglas White, Carnegie UK Trust

Data citizenship: rethinking data literacy in the age of disinformation, misinformation, and malinformation

Elinor Carmi, University of Liverpool

Simeon J. Yates, University of Liverpool

Eleanor Lockley, Sheffield Hallam University

Alicja Pawluczuk, United Nations University

Co-developing digital inclusion policy and programming with Indigenous partners: interventions from Canada

Rob McMahon, University of Alberta

What is critical big data literacy and how can it be implemented?

Ina Sander, Cardiff University

A situated approach to digital exclusion based on life courses

Laura Faure, Fondation Travail-Université

Patricia Vendramin, Université catholique de Louvain

Dana Schurmans, Université catholique de Louvain

Digital youth inclusion and the big data divide: examining the Scottish perspective Alicja Pawluczuk, United Nations University

\section{WHAT DO DIGITAL INCLUSION AND DATA LITERACY MEAN TODAY?}

As more of our everyday lives become digital, from paying bills, reading news, to contacting companies and services, keeping in touch with your friends, lovers and family, and even voting it has become crucial to include everyone in the digital society. If you are not 'online' that means that many opportunities, activities and services are not available to you. But the meaning of digital inclusion keeps on changing and with it also the set of skills, practices, and thinking that are necessary to be 'digital' (Jaeger et al., 2012). What does it mean to be 'online' today?

While these topics are not new, in this special issue we examine the different aspects that people 
are facing with 'being digital' today. Is access to the internet enough, or do people need to understand how the internet works as well? Are we only talking about skills? Do people need different types of literacies for different life stages? Should there be one type of skill and training programme or different ones that cater to people from different backgrounds and needs (ableism, age, education, gender, race, religion)? With disinformation and misinformation spreading across the world, what new challenges and possible approaches should policymakers and educators apply? And do skills have to be associated only with productivity? These questions have been occupying academics, nonprofit and civic sectors, educators, the private sector and policymakers, and as more tasks and everyday life experiences become automated and digitalised, addressing them becomes ever more pertinent.

Digital inclusion is broadly defined as different strategies designed to ensure that all people have equal access, opportunities and skills to benefit from digital technologies and systems (ITU, 2019). Discussions of inequality in the use of digital media and systems have predominantly been framed around the 'digital divide'. They have focused on issues measured by access to the internet and skills such as checking emails, finding information and downloading music (van Dijk and Hacker, 2003). These topics have been key issues for policymakers (Yates et al., 2015a, 2015b) and are central to the development of many governmental digital strategies in Europe, the UK, and the USA. However, since the introduction and widespread use of machine learning and artificial intelligence in different decision making processes relating to citizens' life (health, justice, policing) and onto entertainment (e.g., Netflix and Spotify) and news, research on digital divide and inclusion has shifted. This is because inequalities now involve more complex issues of how these technologies work and what and whom they can influence and may manipulate. It is not that we did not have these problems before, but since people have to use digital systems to do many everyday life activities these have intensified.

In order to include more people in datafied societies countries and organisations have developed different types of literacies. According to Luci Pangrazio and Neil Selwyn (2019) data literacy is the way "individuals might better engage with and make use of the 'personal data' generated by their own digital practices" (Pangrazio and Selwyn, 2019, p. 420). They have developed a 'personal data literacies' framework that focuses on five domains: 1) data identification, 2) data understandings, 3) data reflexivity, 4) data uses, and 5) data tactics. We elaborate more on the different meanings and ideologies behind data literacies in our paper in this special issue, but what is important to understand is that what should be included as part of 'data literacies' keeps on changing and evolving.

Another issue that has proliferated in the past decade relates to different types of information manipulations, often called 'fake-news', disinformation and misinformation. The direct or indirect distribution of intentionally false or skewed information is often meant to shape people's opinions and hopefully actions towards a specific cause (like election results). This spreading of mis- and dis-information by governments, private individuals through sharing, and deliberately by trolls, augmented via automated bots, creates a need for citizens to have new forms and levels of digital literacies. These include digital understanding of how the internet works (Doteveryone, 2018, 2020), how to engage with online news (e.g., fact checking), how digital advertising / adtech works (ICO, 2019), and how to use different tools to be able to control and manage the type of information shared with other parties. This shift has become central to some governmental digital strategies, such as those of the UK Department for Digital, Culture, Media and Sport (DCMS) Online Harms White Paper (2019) and their equivalents around the globe, in countries such as Brazil, India, and the USA, or the Norwegian Ombudsman (Forbrukerrådet, 2018). After the Cambridge Analytica scandal, governments have 
realised the power of technology giants like Facebook, Google, Amazon and Microsoft, to shape and influence people's behaviour. Consequently, many aim to regulate and force platforms to change how they are designed and the way they present information (from content to advertisements). But beyond technological and legal solutions countries seem to be quite puzzled when it comes to inclusion and literacies.

This special issue draws on research, policy, and practice developments around literacies in various regions and contexts, and highlights the politics around them. Over time digital inequalities, digital inclusion and data literacies have changed in response to developments in digital technologies and media. However, key themes have remained, such as: material and financial access to technological devices and services; skills and digital literacy; effective use by citizens and communities to participate in political and civic discussions and activities; the impact of socio-economic factors; motivation and attitudes; and, more recently socio-economic and socio-cultural variations in patterns of usage. Digital inequalities therefore have become an important part of broader persistent issues of social equity and justice. In the next sections we will discuss the most prominent debates around digital inclusion and highlight what is still relevant and what needs to be reevaluated due to our current times.

\section{INCLUSION THROUGH DIGITAL MEANS}

Before we continue it is important to define what literacy means. This is a contested term which means different things to different people in different places. UNESCO has been a key player in trying to tackle media literacy, founding the Grünwald Declaration on Media Education of 1982 (1983). This Declaration was a recognition that there is a need for an educational system to enhance citizens' - of all ages - critical understanding of media and communication. They called for the promotion of analysis of media products, the use of media as means of creative expression, and effective use of and participation in available media channels. According to UNESCO, "[l]iteracy is the ability to identify, understand, interpret, create, communicate and compute, using printed and written materials associated with varying contexts. Literacy involves a continuum of learning in enabling individuals to achieve their goals, to develop their knowledge and potential, and to participate fully in their community and wider society" (Montoya, 2018). According to Silvia Montoya (2018) from UNESCO, there are three main emphases around this definition: 1) The uses people make of literacy to communicate and express themselves through different media; 2) Literacy is plural, it is used in multiple contexts and for multiple purposes; 3) Literacy is a continuum. Taken together with the data literacy definition we can expand this notion and argue for data literacies, meaning identification, understanding, reflexivity, uses and tactics, not only in regards to personal data but all types of data and media.

Literacy issues around reading and writing have been troubling countries for many years but with the introduction of the microprocessor in 1971 (switching the world to digital) and the IBM personal computer in 1981, and in wider capacity the commercial use of the World Wide Web from 1994 - citizens started to engage with computers and the internet across all areas of social, civic and political life. These developments have moved many countries to a digital economy, which demands people to have the appropriate skills and competences to use these new technologies to produce and distribute products and services. At the same time, these technologies also opened new ways to communicate between people, and so beyond the economic aspect of the widespread use of digital systems they have diffused to every aspect of life from personal, art, culture, health, politics and even sex. 
So what kinds of new considerations need to be taken into account when we talk about digital literacy? According to Jaeger et al. (2012), “[d]igital literacy encompasses the skills and abilities necessary for access once the technology is available, including a necessary understanding of the language and component hardware and software required to successfully navigate the technology" (Jaeger et al., 2012, p. 3). But what exact skills and abilities people need and what we mean by successful navigation differ quite radically from person to person. Some scholars have focused on particular skills that children and young people need (Unsworth, 2006; Livingstone and Helsper, 2007; Livingstone, 2009). As children and young people use mobile phones and various online services they are more exposed to risks such as cyber-bullying, exposure to inappropriate content and various privacy issues (such as distribution and editing of sensitive photos to others, sometimes called 'revenge porn'). These require, as Livingstone et al. (2017) argue, parental mediation which involve "'active' mediation along with safety mediation and activities that might seem restrictive (use of technical controls and parental monitoring) but are better interpreted as building a safe framework precisely so that children's positive uses of the Internet can be encouraged" (Livingstone et al., 2017, p. 98). Nevertheless, parents who are less literate in digital technologies will also be more restrictive in their parental mediation and hence people's approaches and understanding are also affected by their surroundings. This means that context, culture (for example there are more restrictions when it comes to girls) and communities have implications on people's literacies.

Others focus on the type of skills and education programmes needed for people with various types of disabilities to be included in the digital society (Williams, 2006; Coyne et al., 2012; Cihak et al., 2015). It is not only that technologies are developed for abled (Bitman and John, 2019) and mostly male, white (Noble, 2018), bodies (Hamraie, 2017) but also the literacy programmes themselves. For example, Darren Chadwick and Caroline Wesson (2016) argue that while the internet offers many new opportunities for people with disabilities to be included in various ways "the interfaces of ICT and associated programmes and applications can be offputting, challenging and extremely difficult to use for those with sensory, cognitive, and physical disabilities" (Chadwick and Wesson, 2016). This also means that they need special, personalised and long term support from their families and beyond in order to be included (Newman et al., 2017). However, 'off-line' inequalities still seem to matter and as Guo et al. (2005) show, disabled people with higher levels of education managed to achieve more access to the internet. As more intersectional consideration started to get attention from scholars and policymakers, it became clear that one-size-fits-all literacy and education programmes will not be suitable for society.

Current policy challenges point to an urgent need to understand and address citizens 'data literacy'. These challenges include: regulatory changes (e.g., the General Data Protection Regulation); public concern over the effects of social media (e.g., disinformation, Cambridge Analytica); repeated data breaches; and growing inequities in the uses of digital media. Part of tackling digital inclusion means to find solutions to the fact that many people are left behind these technological advancements, and that these create what is commonly called - the digital divide.

\section{HOW DO DIVIDES GET DIGITISED?}

The digital divide has been examined for several decades (under various different names). The Organisation for Economic Co-operation and Development (OECD) defined it as: "the gap between individuals, households, businesses and geographical areas at different socio-economic 
levels with regard both to their opportunities to access information and communication technologies (ICTs) and their use of the internet for a wide variety of activities" (OECD, 2001). Initially, in what is commonly called the first wave, scholars have addressed the issue of access to information (via devices in libraries and schools), access to home computers, and access to the internet. The discussion was framed around the 'haves' and the 'have-not' in relation to ownership of computers and access to broadband - hence focused on affordability (Compaine, 2001). This over-simplistic approach was mainly focusing on the technical and economical aspects as ways to 'level-up' people to 'become digital' without taking into consideration social and cultural issues.

One of the most prominent critical voices in this field is Eszter Hargittai who from the beginning of the 2000 s pointed to the problems of presenting this issue in a binary way between those who have access and those who do not. Hargittai proposed a new way to examine the digital divide by focusing on people's differences in levels of skill in finding information online. She also argued that digital inequalities is a better term to use than digital divide - and these have five dimensions: "differences in the technical apparatus people use to access the Internet, location of access (i.e. autonomy of use), the extent of one's social support networks, the types of uses to which one puts the medium, and one's level of skill" (Hargittai, 2001, p. 3). As Hargittai showed, it is not only about owning or having access to technology but also people's social networks and their communities - the divide is not two but multidimensional.

Other scholars who realised the importance of gradations and multiple dimensions are Jan van Dijk and Kenneth Hacker (2003) who proposed an analytical framework by focusing on differential access to skills and usages. By analysing Dutch official statistics the authors point to age and gender gaps. Van Dijk and Hacker outline four types of access gaps: lack of elementary digital experience, no possession of computers and network connection, lack of digital skills and lack of significant usage opportunities. Trying to tune into the nuances of this divide, and in order to have a better assessment of digital divides, they aimed at examining the life experiences and mental barriers of people when using the internet. They proposed the 'strategic skill' which according to them is "the ability to use digital means to improve one's position in society, in work, education, and cultural practices” (van Dijk and Hacker, 2003, p. 324). This strategic skill is related to people's social capital and resources.

After internet use and ownership of computers and mobile devices became widespread in many areas of the world, scholars noticed that divides were still prevalent, and started to examine other issues that might be at play, for example the types of use (Dimaggio et al., 2004). The second wave of scholarship around digital divides has focused on multidimensions and multidisciplinarity of digitally related inequalities. The expansion in research interests started to include the view that other dimensions have influence on digital inequalities, such as political economy (Dahlberg, 2015), gender (Cooper, 2006), internet cultures (Dutton and Reisdorf, 2019), class and status (Wessels, 2013; Yates et al., 2015; Yates and Lockley, 2018) and effects of life courses such as aging, parenting and prison rehabilitation (Robinson et al., 2018).

The third wave, according to Elena Vartanova and Anna Gladkova (2019), can be framed as new divides and negative consequences on society as it "became clear that the digital divide was not a static phenomenon but one heavily influenced by changes taking place on both the national and the global level (uneven development of the internet connection in different regions, the growth of e-commerce and e-democracy, changing audience behaviour and consumption practices under the influence of non-linear digital services, the spread of digital content flows, etc" (Vartanova and Gladkova, 2019, p. 197). Others like Massimo Ragnedda call this a third level 
digital divide whereby "the possibilities that the Internet offers to citizens in economic, political, social and cultural areas are not exploited by everybody in the same way. Social strata that already enjoy social advantages become further privileged. The Internet influences possibilities for citizens to improve their life chances, but in a vicious circle, based on their original social position" (Ragnedda, 2017, p. 28). This stage can be characterised as focusing on intersectional inequalities.

It is important to emphasise, though, that while there has been development of scholarship around digital divide, the way it is applied by governments does not necessarily follow a linear progression. A good example of the way education and training programmes depend on a government's or organisation's position over literacies can be illustrated in recent governmental responses to the Covid-19 crisis. During the global pandemic many governments were rushing to 'solve' the situation with contact tracing apps without thinking that people need to have an understanding of how to use them. Since education programmes tend to be more expensive and time consuming the approach is usually focused on access to technology and functional skills. It is not only governments who held this position but also organisations like the Web Foundation who said that along with access to the internet "we all have a part to play to help companies rid their platforms of misinformation" (Web Foundation, 2020). Such approaches show the developing dependence of governments and organisations on big technology companies in a way that prevents them from being critical to thinking beyond tech-solutionist approaches. Just like the digital divide needs social and cultural solutions that attend to systematic inequalities, so does a pandemic.

Similar to the field of digital inclusion, here too the discussion around the digital divide has evolved to be more nuanced and be expanded to contexts where various types of inequalities are exacerbated in a digital society. With the widespread use of algorithms in various everyday life activities the focus has shifted to the ways they create divides.

\section{DATA AND ALGORITHMIC INEQUALITIES}

The next wave of scholarship around the digital divide and inclusion is framed around inequalities and the need for justice. It examines the problems that arise with the introduction of big data, algorithms, machine learning and other (semi)automated systems in everyday life. Attending to these new divides, Mark Andrejevic put forward the notion of a "big data divide", which according to him is "the asymmetric relationship between those who collect, store, and mine large quantities of data, and those whom data collection targets" (2014, p. 1673). Those who are in a position of accessing and analysing data and especially have the processing power can sort society and create long term social differences and classifications.

Building on this, scholars have examined what can broadly be called the algorithmic divide. These scholars point to the fact that without knowing that algorithms are ordering things in particular ways, people tend to believe that the information they search and encounter on different platforms is objective and neutral. According to Kelly Cotter and Bianca Reisdorf:

Without knowledge of algorithmic curation, users lack crucial insight into the various factors influencing who and what reaches them in search results and social media feeds. The absence of this insight undermines an individual's ability to make rational judgments about the information they encounter... This lack of knowledge denies individuals the ability to properly calibrate their reception of information and act on it accordingly. Consequently, disparities in 
algorithmic knowledge create classes of users with the skills to question and critique algorithmic representations of reality and classes more likely to unwittingly internalize the normative discourses inscribed in algorithmic outputs (e.g., search results) (Cotter and Reisdorf, 2020, pp. 748-749)

As they show in their study, social and economic status still has an influence on the way people understand algorithms. However, as they emphasise, algorithmic knowledge does not substitute for a more critical thinking and information literacy, which are both needed for more advanced ways of engaging with datafied technologies. Similarly, Eszter Hargittai et al. (2020) offer methods to examine people's algorithm skills, for example, in-depth one-on-one interviews as they seem "the best way to dive deep into how, if at all, people think about the ways in which systems they use decide what information to show and share" (Hargittai et al., 2020, p. 4). They also criticise the self-reporting method, which, like in previously examined skills, is problematic as people might not provide accurate portrayal and put them on the spot of not knowing.

Trying to develop a typology of algorithm awareness, Gran et al. (2020) outline attitudes among internet users that go from the unaware, uncertain, affirmative, neutral, and sceptic, all the way to the critical. Although they examine people's demographics and education, they do not focus on other factors such as socio-economic status, which as we have shown has an impact on people's data literacy. According to them, "algorithm awareness is better understood as a metaskill, a knowledge or understanding that may improve other digital skills and benefits in general" (Gran et al., 2020, p. 15). Algorithmic skills, then, are another layer of skills that makes division among people, but access and owning computers, laptops and mobile phones are still an issue for many people from more deprived backgrounds.

A new framework to discuss such issues has arisen from data justice, led by the scholar Lina Dencik. As Dencik et al. (2019) argue, the concept of data justice is a response to various societal consequences of data driven technologies and services. As they suggest, the framing of 'data justice' helps to open the debate to multiple fields such as inequalities, discrimination as well as automation and algorithmic decision-making. They aim to pay particular "attention to structural inequality, highlighting the unevenness of implications and experiences of data across different groups and communities in society" (Dencik et al., 2019, p. 875). Similarly, Josef Trappel (2019) examines the digital divide in the context of wider social and information inequalities. According to him, the digital divide is related to a broader history of social exclusions and inequalities, and they "exceed the dimension of information inequality and expand more generally to affect life chances. Given the huge variety of application-based services to master the challenges of daily life, those who are not well connected are likely to be distanced and excluded“ (2019, p. 22). As he argues, this power dynamic of datafication relates to longstanding social, political, economic and cultural issues.

\section{CONCLUSION}

As these fields show, digital inclusion and digital divides are not separate islands, rather they represent fields of research that examine layers of inequality; these layers stack up one over the other, so depending on your starting point in society, be it age, gender, socio-economic status, ability and education - you will have to break through more or less layers of challenges.

So what kinds of policies are needed to include more people in datafied societies and what types of literacies should they learn? Here we outline several suggestions to move forward: 
1. Investing in free public spaces - One of the main issues that emerges from the literature and policies is that there are not a lot of public spaces where people can actually develop their literacies. You will read about NGOs like the Good Things Foundation in this special issue but there is a need for further investment in public spaces. Free public spaces where people can meet, organise and talk have been diminishing with nearly 800 libraries in the UK getting closed in the past decade. Libraries are spaces where people from all types of backgrounds can get free access to the internet, computers and help from librarians who are trained to help people according to their needs (as discussed elsewhere - see Rhinesmith, 2012; Rhinesmith and Stanton, 2018; Strover, et al., 2020). In addition, these are places where different groups can meet and have literacy training for free. When more and more of our society gets privatised it is essential to have these spaces.

2. Community over scale - Following the previous point we want to emphasise the recurring theme of data literacy which is that there is no one-size-fits-all programme. This means that people with different socio-economic background, age, education and ethnicity need to have education programmes that make sense to their everyday lives. Here, local communities are much more effective than programmes that are 'universal'.

3. Long term and ongoing literacies programmes - Another theme that emerges from the literature review is that literacy programmes are oftentimes short lived. They are focused around specific campaigns and usually last for weeks or months. But people need an ongoing learning experience, a place that can provide them support and guidance in case they have difficulties and also monitor their progress. Therefore, and following the point we make above, we think that local communities which have fully staffed libraries and additional funding for new computers and programmes can help to develop a long term and sustainable network of literacy.

4. Distancing from big technology companies - Big technology companies such as Google, Microsoft and Facebook have been providing funding, tools and education programmes to various bodies as you can read more about in Alicja Pawluczuk's paper in this issue. Google for example is also sponsoring various media literacy initiatives such the Guardian's NewsWise. While we think these contributions are given in good faith there is a problem and a conflict of interest. If citizens are to be more critical towards the way different technologies are designed and used there is a need for more funding from governments to develop such programmes and organisations. The funding could potentially come from starting to tax big technology companies.

\section{THE ARTICLES IN THIS ISSUE}

We begin the special issue with three commentaries from practitioners who work for NGOs because we believe that they are an integral part of the discussion around inclusion and literacies.

First, Alice Mathers from the UK nonprofit Good Things Foundation talks about the importance of community based digital literacy projects, including their Skills Enterprise programme. This programme involves volunteers, local university students and provides ongoing support to people who are having difficulties with various services which became digital in the realms of labour, housing and health. Mathers also highlights the fact that while governments are moving fast with different digital initiatives, there are still many who have no or very limited skills. Hence, campaigns like Bridging the Digital Divide is a positive way forward for further including many who are still left behind.

Second, Mary Loitsker from the Israeli NGO Hasanda explains why it is important to teach individuals and organisations how to read government budgets. She argues that by understanding how resources are distributed and spent over time citizens are empowered to ask their representatives hard questions and try to change policies around resource allocation. 
Douglas White from the Carnegie UK Trust in Scotland discusses own projects such as \#NotWithoutMe - designed to help children and young people at risk, to be included. White also shows how times of crisis like Covid-19 deepen digital divides and that in order to include more people online, and having adequate literacies, we need more than just technological solutions.

Next up we have five peer-reviewed academic papers. The first one by Elinor Carmi, Simeon J. Yates, Eleanor Lockley, and Alicja Pawluczuk lays down the basic definitions discussed in the whole issue, their histories and ideologies. The article examines data literacy by showing the ideology behind the concept of literacy and highlighting three differences that data literacy in the age of dis-, mis-, and mal-information has. After that we have four papers who examine data literacy in different contexts while making arguments about theory that stems from their research results.

The second paper is one in which Rob McMahon explores two examples of digital inclusion codeveloped with Indigenous peoples in Canada. One highlights the efforts of the First Mile Connectivity Consortium (FMCC), which developed a model for supply-side digital inclusion that puts communities at the centre and at the start of any digital network development process. The second one revisits a digital literacy initiative in First Nations, Inuit and Métis peoples specific cultural revitalisation activities, adopting and using technologies in situated ways that support the cultural resilience and sustainability of diverse Indigenous communities.

Next we have Ina Sander's paper which proposes a new framework called critical big data literacy that places awareness and critical reflection of big data systems at its centre. Sander examines dozens of different data literacy online tools and outlines a typology of the different approaches. She then explores how people react to these different literacy tools and programmes and argues that interactive and accessible data literacy tools work better, with the need to include visualisations and constructive advice.

The fourth article, by Laura Faure, Patricia Vendramin and Dana Schurmans, proposes a situational reading of digital exclusion by developing an approach based on life stages, such as education, personal and professional. By interviewing Belgian people's moments of transition and rupture within these life stages, they reveal the way people are put at risk of being digitally excluded in key moments, but that the exclusion depends on their individual backgrounds as well as the social context.

Finally, Alicja Pawluczuk's paper argues that youth digital inclusion should be based on young people's everyday practices and not only revolve around employment and education. Focusing on Scottish young people's data literacy programmes, Pawluczuk reveals power asymmetries that relate to big technology companies' involvement (whether in funding, facilities, software or actual training) in literacy programmes and the problems associated with that. In order to advance young people's inclusion, Pawluczuk proposes three dimensions that need to be present: 1) digital youth inclusion provision; 2) a holistic understanding of young people's feelings and aspirations; and 3) amplifying human rights.

Taken together, we believe that this special issue provides a snapshot of the burning issues around digital inclusion and data literacy at the time of writing. With the rapid changes of technology and involvements of big technology companies in every aspect of our society, we will need to keep developing new programmes that attend to people being included in the datafied society. At the same time, as the different papers emphasised, there is a need for more scrutiny, critical thinking and proactive actions from citizens to hold technology to account, challenge the tech-solutionism narrative and put people at the centre, not profit. 


\section{REFERENCES}

Andrejevic, M. (2014). The big data divide. International Journal of Communication, 8, 1673-1689. https://ijoc.org/index.php/ijoc/article/view/2161

Bitman, N., \& John, N. A. (2019). Deaf and hard of hearing smartphone users: Intersectionality and the penetration of ableist communication norms. Journal of Computer-Mediated Communication, 24(2), 56-72. https://doi.org/10.1093/jcmc/zmyo24

Chadwick, D., \& Wesson, C. (2016). Digital inclusion and disability. In A. Attrill, \& C. Fullwood (Eds.), Applied cyberpsychology (pp. 1-23). Palgrave Macmillan.

https://doi.org/10.1057/9781137517036_1

Cihak, D. F., Wright, R., Smith, C. C., McMahon, D., \& Kraiss, K. (2015). Incorporating functional digital literacy skills as part of the curriculum for high school students with intellectual disability. Education and Training in Autism and Developmental Disabilities, 5O(2), 155-171. https://www.jstor.org/stable/24827532

Compaine, B. M. (2001). The digital divide: Facing a crisis or creating a myth? The MIT Press.

Cooper, J. (2006). The digital divide: The special case of gender. Journal of Computer Assisted Learning, 22(5), 320-334. https://doi.org/10.1111/j.1365-2729.2006.00185.x

Cotter, K., \& Reisdorf, B. C. (2020). Algorithmic Knowledge Gaps: A New Dimension of (Digital) Inequality. International Journal of Communication, 14, 745-765.

https://ijoc.org/index.php/ijoc/article/view/12450

Coyne, P., Pisha, B., Dalton, B., Zeph, L. A., \& Smith, N. C. (2012). Literacy by design: A universal design for learning approach for students with significant intellectual disabilities. Remedial and Special Education, 33(3), 162-172. https://doi.org/10.1177/o741932510381651

Dahlberg, L. (2015). Expanding the digital divides research: A critical political economy of social media. Communication Review, 18(4), 271-293.

https://doi.org/10.1080/10714421.2015.1085777

Dencik, L., Hintz, A., Redden, J., \& Trere, E. (2019). Exploring Data Justice: Conceptions, Applications and Directions. Information, Communication \& Society. 22(7), 873-881. https://doi.org/10.1080/1369118X.2019.1606268

Department for Digital, Culture, Media \& Sport (DCMS). (2019). Online Harms White Paper. https://www.gov.uk/government/consultations/online-harms-white-paper

Dimaggio, P., Hargittai, E., Celeste, C., \& Shafer, S. (2004). Digital inequality: From unequal access to differen-tiated use. In K. Neckerman (Ed.), Social inequality (pp. 355-400). Russell Sage Foundation.

Doteveryone. (2018). People, Power, and Technology - The 2018 Digital Understanding Report. https://www.doteveryone.org.uk/report/digital-understanding/

Doteveryone. (2018). People, Power, and Technology - The 2020 Digital Attitudes Report. https://www.doteveryone.org.uk/report/peoplepowertech2020/.

Dutton, W. H., \& Reisdorf, B. C. (2019). Cultural divides and digital inequalities: attitudes 
shaping Internet and social media divides. Information, Communication \& Society, 22(1), 18-38. https://doi.org/10.1080/1369118X.2017.1353640

Forbrukerrådet (2018). Deceived by Design: How tech companies use dark patterns to discourage us from exercising our rights to privacy. https://fil.forbrukerradet.no/wpcontent/uploads/2018/o6/2018-06-27-deceived-by-design-final.pdf.

Gran, A. B., Booth, P., \& Bucher, T. (2020). To be or not to be algorithm aware: a question of a new digital divide?. Information, Communication \& Society.

https://doi.org/10.1080/1369118X.2020.1736124

The Grünwald Declaration on Media Education. (1983). Educational Media International, 2O(3), 26-26. https://doi.org/10.1080/09523988308549128

Guo, B., Bricout, J. C., \& Huang, J. (2005). A common open space or a digital divide? A social model perspective on the online disability community in China. Disability \& Society, 2O(1), 49-66. https://doi.org/10.1080/0968759042000283638.

Hargittai, E. (2001). Second-level digital divide: Mapping differences in people's online skills. arXiv. https://arxiv.org/abs/cs/0109068

Hargittai, E., Gruber, J., Djukaric, T., Fuchs, J., \& Brombach, L. (2020). Black box measures? How to study people's algorithm skills. Information, Communication \& Society, 764-775. https://doi.org/10.1080/1369118X.2020.1713846

Hamraie, A. (2017). Building access: Universal design and the politics of disability. University of Minnesota Press.

ICO. (2019). Adtech - Market Research Report. https://ico.org.uk/media/about-theico/documents/2614568/ico-ofcom-adtech-research-20190320.pdf

ITU. (2019). ITU-D Digital Inclusion. https://www.itu.int/en/ITU-D/DigitalInclusion/Pages/default.aspx

Jaeger, P. T., Bertot, J. C., Thompson, K. M., Katz, S. M., \& DeCoster, E. J. (2012). The intersection of public policy and public access: Digital divides, digital literacy, digital inclusion, and public libraries. Public library quarterly, 31(1), 1-20.

Livingstone, S. (2009). Children and the Internet. Polity.

Livingstone, S., \& Helsper, E. (2007). Gradations in digital inclusion: Children, young people and the digital divide. New Media \& Society, 9(4), 671-696.

https://doi.org/10.1177/1461444807080335

Livingstone, S., Ólafsson, K., Helsper, E. J., Lupiáñez-Villanueva, F., Veltri, G. A., \& Folkvord, F. (2017). Maximizing opportunities and minimizing risks for children online: The role of digital skills in emerging strategies of parental mediation. Journal of Communication, 67(1), 82-105. https://doi.org/10.1111/jcom.12277

Montoya, S. (2018). Defining Literacy. UNESCO.

http://gaml.uis.unesco.org/wp-content/uploads/sites/2/2018/12/4.6.1_07_4.6-defining-litera cy.pdf 
Newman, L., Browne $\square$ Yung, K., Raghavendra, P., Wood, D., \& Grace, E. (2017). Applying a critical approach to investigate barriers to digital inclusion and online social networking among young people with disabilities. Information Systems Journal, 27(5), 559-588.

https://doi.org/10.1111/isj.12106

Noble, S. U. (2018). Algorithms of oppression: How search engines reinforce racism. New York Press.

OECD. (2001). Annual report. OECD Publishing.

Pangrazio, L., \& Selwyn, N. (2019). 'Personal data literacies': A critical literacies approach to enhancing understandings of personal digital data. New Media \& Society, 21(2), 419-437. https://doi.org/10.1177/1461444818799523

Ragnedda, M. (2017). The Third Digital Divide: A Weberian approach to digital inequalities. Routledge. https://doi.org/10.4324/9781315606002

Rhinesmith, C. (2012). Free library hot spots: Supporting broadband adoption in Philadelphia's low-income communities. International Journal of Communication, 6, 2529-2554.

https://ijoc.org/index.php/ijoc/article/view/1782

Rhinesmith, C., \& Stanton, C. L. U. (2018). Developing media literacy in public libraries: Learning from community media centers. Public Library Quarterly, 37(4), 420-440. https://doi.org/10.1080/01616846.2018.1525527

Robinson, L., Chen, W., Schulz, J., \& Khilnani, A. (2018). Digital inequality across major life realms. American Behavioral Scientist, 62(9) 1159-1166.

https://doi.org/10.1177/ooo2764218773800

Strover, S., Whitacre, B., Rhinesmith, C., \& Schrubbe, A. (2020). The digital inclusion role of rural libraries: social inequalities through space and place. Media, Culture \& Society, 42(2), 242-259. https://doi.org/10.1177/0163443719853504

Trappel, J. (2019). Digital Media Inequalities: Policies against divides, distrust and discrimination. Nordicom.

Unsworth, L. (2006). E-literature for children: Enhancing digital literacy learning. Taylor \& Francis. https://doi.org/10.4324/9780203412954

van Dijk, J., \& Hacker, K. (2003). The digital divide as a complex and dynamic phenomenon. The information society, 19(4), 315-326. https://doi.org/10.1080/01972240309487

Vartanova, E., \& Gladkova, A. (2019). New forms of the digital divide. In J. Trappel (Ed.), Digital media inequalities: Policies against divides, distrust and discrimination (pp. 193-213). Nordicom.

Web Foundation (2020). The web can help more in the fight against Covid-19. Here's what we must do [Blog post]. https://webfoundation.org/2020/o3/the-web-can-help-more-in-thefight-against-covid-19-heres-what-we-must-do/.

Wessels, B. (2013). The reproduction and reconfiguration of inequality: Differentiation and class, status, and power in the dynamics of the digital divides. In M. Ragnedda \& G. W. Muschert (Eds.), The digital divide: The internet and social inequality in international 
perspective (pp. 17-28). Routledge.

Williams, P. (2006). Exploring the challenges of developing digital literacy in the context of special educational needs communities. Innovation in Teaching and Learning in Information and Computer Sciences, 5(1), 1-16. https://doi.org/10.11120/ital.2006.05010006

Yates, S., Kirby, J., \& Lockley, E. (2015a). Digital media use: Differences and inequalities in relation to class and age. Sociological research online, 2O(4), 71-91.

https://doi.org/10.5153/sro.3751

Yates, S. J., Kirby, J., \& Lockley, E. (2015b). 'Digital-by-default': Reinforcing exclusion through technology. In L. Foster, A. Brunton, C. Deeming, T. Haux (Eds.), Defence of Welfare 2 (pp. 158-161). Policy Press.

Yates, S., \& Lockley, E. (2018). Social media and social class. American Behavioral Scientist, 62(9), 1291-1316. https://doi.org/10.1177/ooo2764218773821 